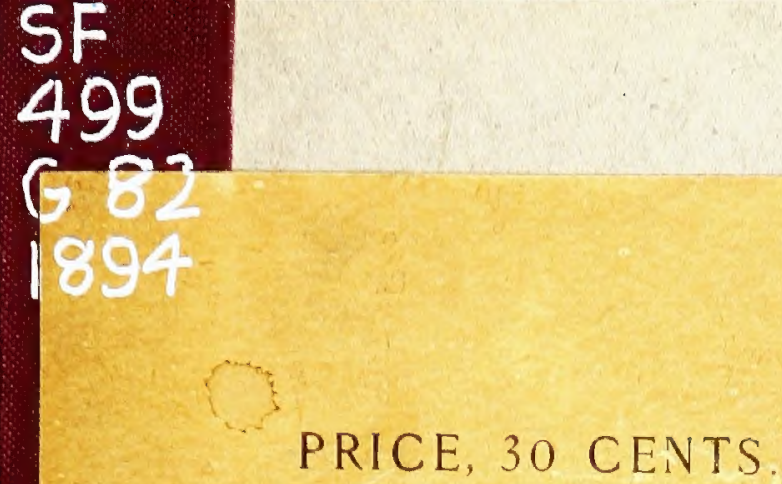

PRICE, 30 CENTS.

@APONS
PROFIT.

BY T. GREINER. 


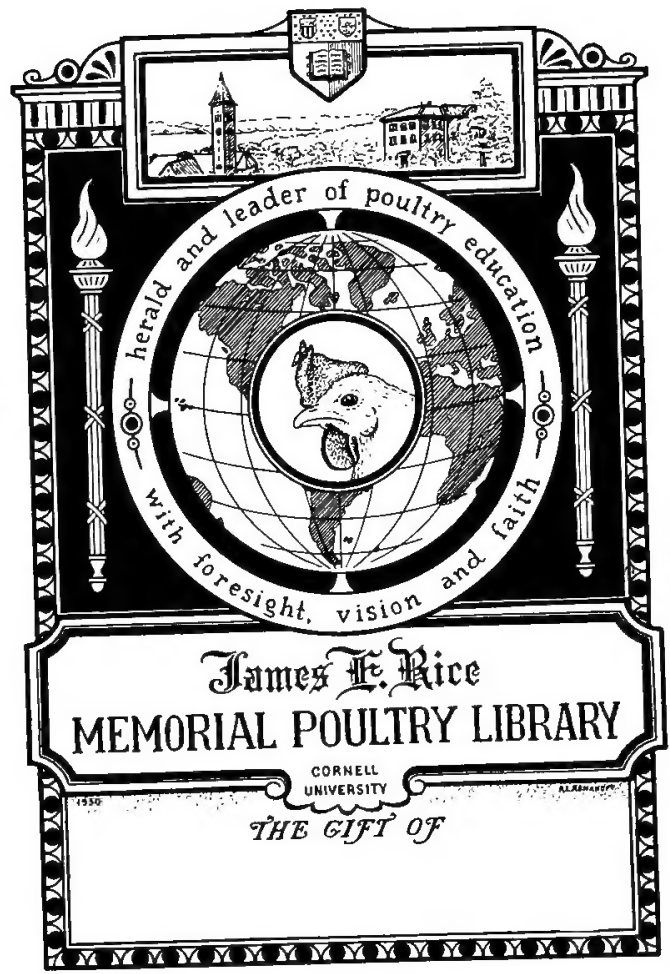




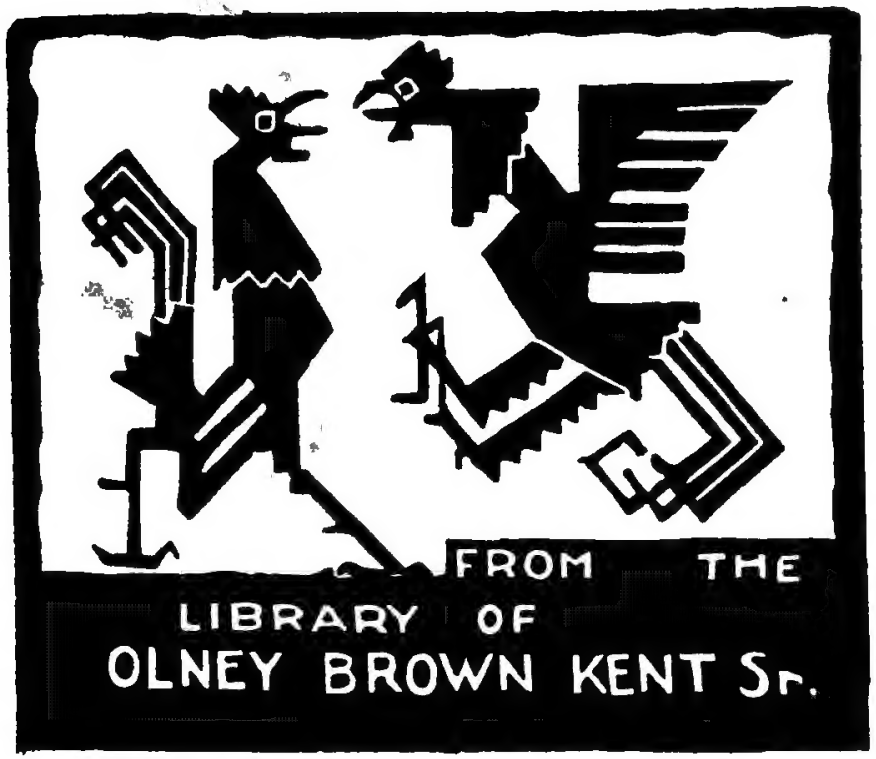




\section{Cornell University Library}

The original of this book is in the Cornell University Library.

There are no known copyright restrictions in the United States on the use of the text. 


\title{
CAPONS FOR PROFIT.

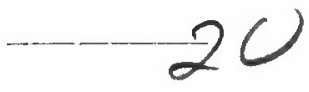

HOW TO MAKE

AND

HOW TO MANAGE THEM.

Plain Instructions given by a Beginner for the Beginner.

\section{IエエUSTRATED.}

T. GREINER, LaSALlE, N. Y. $=$

\author{
From The Librany of $B 7$ \\ Dr. Olney Brown Kent
}




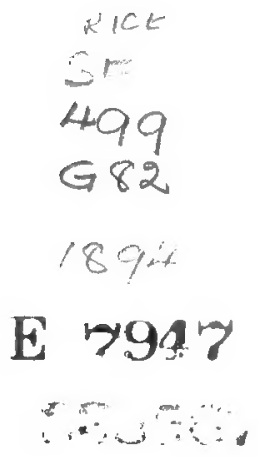

COPYRIGHTED, 1893.

BY T. GREINER, LA SALLE, N. Y. 


\section{1 \\ THE TRUTH ABOUT POULTRY.}

A FRIENDLY TALK THAT MAY SERVE AS AN INTRODUCTION.

I AM not a novice in the poultry business. As an apprentice I have served long and faithfully, but I am an apprentice, a learner, still, and expect to be one as long as I live. My interest in poultry is about as old as my memory. I was not yet in my teens when I made my first practical experiment in chicken raising, by inducing a pair of fancy pigeons to adopt an ordinary hen's egg for hatching in place of their own two little eggs. Well do I remember the pleasurable excitement that thrilled The Boy's and throbbed all through my whole
Firut ohick.
being when I found the little chick trying to get out of the shell, and how I had to run to tell my mother, all aglow with pride and joy. Then how I watched, fed and petted the little motherless thing for a few days, until an unlucky accident 
put an end to its life and to my enjoyment. I could not have grieved more had I lost a fortune.

A dozen years later, at the age when a person knows more than all the rest of mankind, I could see golden opportunities in poultry raising as a business Poultry papers and poultry writers had told me of the lot of money that might be made by raising chicks and eggs for market. Estimating profits on paper, from imaginary figures, is always an easy enough matter. One hen gives $\$ 1.00$ a year clear profit; 1,000 hens must give $\$ 1,000$. That was as clear as day light, and needed no proof. Anyhow, if I had no acquaintance with the real facts, I had unlimited faith in these figures, for figures can-

Do Iigures Lie? not lie; and if I was without practical experience, I was fully convinced of my own superior smartness. If others had succeeded, I could, and possibly in a greater degree. So I made my plans, and racked my brains about the construction of an incubator and brooders, etc., things little thought of in those times. Next I began active operations with about 150 laying hens which were kept for the purpose of getting eggs to sell in the open market. It did not take.me long to find out that 150 hens housed in one building, no matter how large, will not lay 10 times as many eggs as 15 hens kept by themselves, and given a large range. Grain was then much dearer than it is now, although I grew what corn and oats I needed, and eggs were selling at the lowest prices I have ever either paid or received for them. In short the outcome was so discouraging that, instead of increasing my stock of layers, as originally intended, 
to 1,000 hens, I decreased my number to 35 or 40 , a number more nearly in harmony with the conditions of the farm and the market. Experiments with incubators and brooders were entirely given up.

In $1885 \mathrm{I}$ moved to New Jersey. The higher prices which prevail near the large cities and the summer resorts along the beach for spring chickens and eggs revived my interest in the poultry busi-

ness. I made a new start with Black

Poultry Experience Langshans, and soon had as fine a
in Now Jorsey. flock of from 100 to 200 fowls as any one could wish to see. Grain was now reasonably cheap. I used to buy a second grade of wheat at my feed-dealer's at 80 or 85 cents a bushel, and corn in the ear from some neighbor at 25 cents a bushel ears; bran and other ground feed in proportion. Fish, fish refuse and crabs were easily obtained, and largely used to furnish the desired animal food. $\mathrm{My}$ nearest grocer a]ways bought my cockerels when 2 or $2 \frac{1}{4}$ pounds in weight, paying 1.00 per pair alive. Eggs were mostly sold for hatching purposes, at $\$ 1.50$ per setting when shipped, or 50 cents per setting to people who came after them. Hens laid well. Sometimes I had to sell the eggs to the groceryman, and always received for them from 18 to 36 cents per dozen. I had two yards of moderate size and a one-half acre orchard fenced in. In gardening time my fowls were kept inside these fences, at other times they were allowed to roam at will over meadows and fields. There was some work and care connected with this enterprise, but on the whole it proved interesting and satisfactory. My books showed a clear annual protit of from 75 cents 
to $\$ 1.00$ per hen. 'This result was obtained under an unusual combination of favorable conditions; but I had already reached the limit to which I could hope to extend the business safely and profitably. Where the conditions are less favorable (and that is the usual case), either the number of fowls kept must be decreased accordingly, or the profits will dwindle down rapidly.

Poultry as ordinarily kept on the farm and other rural homes (in limited numbers mainly) does pay, and usually pays better than any other kind of farm stock. There cannot be a particle of doubt about it. The anxious question, "Does poultry-keeping pay?" can only have reference to extensive operations. When I hear of any one, who is out of profitable employment, starting out to keep 1,000 hens for egg laying, or to raise spring chickens by means of incubators and brooders, I always feel sorry for him, and make up my mind that after a while he will have a bigger stuck of experience and a smaller amount of money. 1 say this advisedly. I well remember the delightful day I once spent with poultry editors Jacobs and Wholesale Poultry Boyer, visiting the chicken-rearing
Eatablishments. Eatablishments. establishments in Hammonton, $\mathbf{N}$ J. What I saw there interested me greatly, but it did. not fire up my enthusiasm to the point of making me take hold of the business. Right there, with climate and soil conditions about as favorable as one might imagine, with good counsel to be had at first hand from the older neighbors who diligently, perseveringly, but carefully, had worked their way gradually into moderate success, with plenty of 
local experience in selecting and running incubators and brooders, with near markets ready to receive the product, the chances seemed in every way to favor success. Yet even then I noticed the impulsiveness and impatience of the younger element that was taking hold of the business, and the rashness with which they rushed in where the older and more experienced ones had feared to tread. I could not overlook the fact that, while there were some moderate successes on a moderate scale, large-scale operations were yet in an experimental stage, and I foresaw that there would be a liberal sprinkling of failures among the successes.

I have also watched with interest the start and development of other large poultry enterprises elsewhere, but found that final failure was the rule, and moderate success the exception. In short, I have seen so much of this, that I feel perfectly safe in prophesying failure, when I see one of the smart young fellows embark in poultry raising with a full equipment of incubators, brooders, etc; but without previous practical experience. Theories in this field are terribly misleading.

- But as I said before, poultry in the usual numbers on the farm are a paying stock. And yet they can be made to pay still better than they really do now. The ordinary management is abominable. The scrub stock so generally met with Poultry until only a few years ago, is fortunately on the Farm. less common, and signs of nixture of blooded stock, especially of Plymouth Rock, Leghorns, etc., may be seen everywhere. This is at least one great step in advance, but it is only one, 
and more improvements in management are needed. One of them is in the matter of feeding. Corn is yet fed by far too extensively and exclusively. It is not a fit grain to be used in this manner. Wheat is cheap, and considering its value as a flesh and egg producer, much cheaper than corn. It can and should be made use of for poultry feed much more extensively than it now is.

Then there is this matter of keeping useless males. They are allowed to comsume a large share of the food that might be made to produce eggs, and meat worth five or ten cents a pound more than that of old roosters. I keep one male bird for 30 to 50 hens, and the chicks I raise are strong and healthy, apparently every egg being fertile. What is the use of feeding three or four old roosters when one will do as well or better? They do more harm than good. Where hens are kept to lay eggs for table use, not for latching, we can go much further, even, and dispense with males entirely. 


\section{II. \\ CAPON PHILOSOPHY.}

\section{WHAT IS A CAPON, AND WHAT IS HE GOOD FOR?}

I HAVE to say something more about keeping males. About one-half the number of chicks in any flock are males. If they are early, so to be fit for "roasters" in June or July, you should always dispose of them at that time at the high prices then obtainable. You will make more money selling your two-and-a-half or three 0ld Roosters Not pound cockerels at 25 or 30 cents a
Wanted. pound than by selling five or six pound roosters at ten cents a pound in late fall or winter. Don't keep "spring chickens" until they are old roosters. The question often is what to do with the later young cockerels. When they are of "spring chicken" size, autumn is fast approaching; the demand for "spring chickens" is past and the call is for old hens. To keep the young cockerels over means to raise a lot of old cocks of little value. I cannot afford to raise that kind of stock. They are a nuisance on the place, always mischievous, harassing laying hens and reducing 
the profits, and at best they will bring only eight or ten cents a pound, that has cost you more than that amount to produce. My way now is to turn them into capons, and thus double the value of their flesh.

There are a great many persons in America who have never heard of capons, and have not the least idea what they are.

"What a magnificent lot of fowls!"

"Say, Mister, what breed are your fowls?"

"Will you sell me a trio of your fowls, or a setting of eggs in the spring?"

These are questions that I and some of my friends who keep a goodly number of capons, have been asked time and time again; and we had to explain the matter as best as we could. If we simply said "They are capons," people would answer, "Why, yes; they are just the breed we want." I think myself that they will want them after they once find out how tender and sweet and juicy their flesh is.

But what are capons, anyhow? Farmers make oxen of their surplus male calves, and wethers of their surplus male lambs, and ordinary horses of their male colts. In short, they castrate or emasculate all male animals not wanted for breeding purposes. Occasionally male cats and dogs are treated in the same way; and the process of castration gives us better cats and dogs than they are in their unaltered state. We used to castrate male rabbits when we were breeding them for table use, and it improved them greatly in size and quality of flesh, and as in other animals, made them more peaceable and quiet.

But while thus improving by castration the surplus males of all farm stock, farmers have neglected 
the male chickens, probably considering them beneath their notice in this respect.

This is a big mistake.

It is easier to castrate a young cockerel than a pig or a lamb. It is profitable in more ways than one. Once operated on, capons become the Why most tractable and peaceable animals we Caponize. imaginable. They do not run, nor chase, nor fight. All they seem to live for is to eat and grow and become fat. I will not say that capons while young grow faster, or lay on more flesh from a given amount of food than unaltered males of the same age do. As long as the cockerel is young enough so that no energy goes into the reproductive organs, I think their development is about at an even rate. But there is a change after a time. The development of the organs of reproduction in the male, and his growing activity and restlessness consume energy, which is saved in the capon for flesh production.

Water only comes to a certain degree of heat. All the excess above this is utilized for the formation of steam. It is the same thing with the rooster. $\mathrm{He}$ grows to a certain size or weight, and all the surplus energy above this is used for the purpose of reproduction. In other words, the capon will continue to grow and lay on flesh much longer than the unaltered male. It takes a year or more for the capon to come near his full size and weight, but at that age he is much larger than the rooster of the same age, and several times as valuable. A pound of old rooster is worth from 6 to 10 cents; a pound of capon from 18 to 28 cents. 
Capons stand crowding. While there is a limit to the number of laying hens that one can keep with profit, there is practically no limit to the number of capons. You can keep as many as you have room for. They will do just as well when in a flock of a hundred, than when there are only a dozen. They are hardy, and remarkably exempt from disease. Their appearance and bearing is peculiar, but they are handsome and interesting nevertheless.

I have always felt a great interest in the subject of capon making. But I can tell you that I have never taken more comfort among my poultry, or felt prouder of them, than I am doing this year among my first good-sized flock of capons 


\section{III.}

\section{SOMETHING ABOUT THE CAPON MAKER.}

\section{PEOPLE WHO CAN CAPONIZE AND PEOPLE WHO SHOULD KEEP THEIR HANDS OFF.}

THERE are people whom I would not advise to undertake the operation of caponizing. The person to do it should have, above all things, faith in his undertaking and in himself. He must be convinced that his work is right, and then go ahead. This is no place to make a trial for fun, or in a halfhearted way. It is a little of the genuine enthusiasm that is needed, and that is bound to overcome difficulties should any be encountered. Then there should be an average amount of mechanical skill and the same amount of nerve. Clumsy fingers have no business in operating on a live fowl. If you are a little nervous at first, it will do no hurt. Your nervousness will wear off after you operFaith and ate on two or three fowls, and see how
Nerve. easy the job is, and how little pain it apparently causes to the bird. You must have full 
confidence in your ability to do it just right, and then go ahead without fear and trembling. And when you are at it once it is far better to operate on all the fowls ready for the operation in one day than fuss along with two or three every few days. The beginner is apt to be a little nervous when he goes for the first bird; but after he gets his hand in once, everything moves off smoothly and nicely. His hand becomes steady, and the work passes off rapidly. Of course, it is an advantage if you can see some one perform the operation, even on a single bird. No more is needed to teach you the whole operation. But the average person does not often have a chance to see it done.

We ourselves had to learn it from books and printed instructions-not very plain ones eitherand succeeded beyond expectations. After a few days' practical experience I thought nothing of caponizing 20 birds before dinner. The operation, indeed, after you have once undertaken it and succeeded, is an easy enough thing, and causes but little pain and inconvenience to the bird, if you do it right and with proper tools. A good set of tools, of course, is utterly indispensable, and the person unwilling to expend $\$ 2$ or $\$ 3$ for them is not included in the list of persons who can safely undertake the operation.

Then there are some timid souls who tremblingly ask, "Does it hurt?" The farmer when castrating lambs, or pigs, or calves, etc., does not Nocessity Not ask, "Is it cruel?" The butcher, when
cruelty. he kills a sheep, or hog, or calf, does not stop inquiringly, "Does it hurt?" Both know 
well enough that they do inflict some pain to their victims. But they yield to the demands of necessity. We can not always avoid suffering pain, or giving pain.

What is cruelty? The needless infliction of pain. This is cruelty and decidedly a wrong. Yet many persons, too tender-hearted to stick a pig, or to castrate a hog, or to have a boil on their own back lanced, will, when provoked, use the whip freely on their children, or kick and strike their horses and cows most unmercifully on slightest provocation.

All this is a needless infliction of pain, and therefore cruelty and inhumanity. We can and should be merciful and decent, all the more $\Delta$ Plea when we are compelled to make other for Humsnity. When we are compelled to make other to insert a hog-hook into a hog's mouth and pull the animal into the scalding vat before it is dead. It is not necessary to begin skinning a calf or lamb when yet alive. I think these things are horrible, and people of any heart and feeling would not stoop to do things so mean.

Nor do I think that it is merely a necessary and legitimate infliction of pain, or even reconcilable with mercy and decency, and the ordinary instincts of humanity to kill and dress fowls in the horrible manner practiced by many, and as I have seen it advised even by a renowned poultry editor. To strip a fowl of feathers while suffering from a death wound in the throat, and to have it dressed clean before it is dead, seems to me a crime for which the perpetrator himself ought to suffer. The French killing knife is made for the purpose of being inserted into 
the bird's brain, causing instant paralysis and insensibility before the stripping process begins.

In short, the person whom I would like to induce to turn mischievous, worthless cockerels into peaceable and valuable capons, is the one who is impressed with the necessity and advantages of the operation; who has faith in his abilities, an ordinary amount of mechanical dexterity and nerve, a little energy and perseverance, and is in possession of the tools needed for the operation. This man is neither a sensitive weakling nor a cruel brute.

People too morbidly sensitive to use the knife on a live bird; people with clumsy fingers; people without proper tools, or people who are brutes, are the people whom I would wish to keep their hands off this business. 


\section{IV. \\ THE VICTIMS AND THE TABLES.}

BEST BIRDS AND BEST BREEDS FOR BEGINNERS-SIMPLE OPERATING TABLES.

$T$ HERE is a great difference in breeds and birds. I was especially fortunate in the materials I had at hand. In the first place, I have for many years taken an especial fancr to the Langshan breed, and the cockerels with which I had to make my first trials were either the pure black Langshan or crosses of Langshan cock and Plymouth Rock hen. Of all breeds I have tried I find the Langshan the easiest subject to operate on, because the bird makes bone first and flesh afterward, in other words, is asually lean when young, showing the ribs quite prominently. It offers little difficulty to the prompt removal of the testicles, and

Langshen
at the Head. apparently is suffering the least while at the Head. under the operation. Besides this, the Langshan has the ad vantage of large size and great hardiness. It is also less liable to make what is known as "slips" than most other breeds.

My next choice would be the Langshan and Plymonth Rock cross. The cockerels, in plumage and 
outward appearance, resemble Plymouth Rocks quite closely, yet offer about as little difficulty to the novice as the pure Langshan. They make large, noble-looking capons. Most of the ordinary mixed fowls of our barn-yards are easily operated on. Cochins I have never tried. Of course, they are large and will make good capons.

Brahmas will grow to largest size, and may prove the most profitable of all breeds for this purpose, yet the beginner will be apt to have trouble with them. The ribs do not show prominently on the outside. Although this makes little difference to a person after he has operated on a number of fowls it may puzzle the beginner. The most serious stumbling block, however, is the shape of the testicle, which in young Brahma cockerels is about a half inch long, extending close and worm-like along the big artery: To slip a horse-hair loop around the Brahma testicle, so that it will catch on and cut its way between the testicle and the artery, is no small job for the beginner. I would have not succeeded quite so well with Brahmas except for the use of steel wire in place of horse-hair. My emphatic advice, therefore, is to make the first trial with easy caponizers, especially the Langshan or Langshan cross, or with ordinary smaller breeds, never with Brahmas.

We are now trying the Indian games. These excel in quality, and will probably make the choicest capons for home use. The markets, however, do not yet discriminate between capons of different breeds except so far as size is concerned. For profit we want the fowls that will give us the greatest 
weight-Langshan, Cochin, Brahma, Plymouth Rock.

I also find that it is less trouble to operate on comparatively young subjects than on older and larger ones. When I want an easy job I take a two pound Langshan, Langshan cross or Plymouth Rock. My Langshan-Plymouth Rock crosses seldom flinched eren when the incisions were made or the testicles twisted off, while Brahmas, which are usually taken at more advanced age and size (four ponnds or more) offer more or less resistance, and must be held more firmly.

It is also a good plan to use a dead subject for the first lesson. Shut the victim up without food or drink for 36 hours. This is important, as you want the intestines empty. Then chop his head of, put him on the operating table in good light, and otherwise in the same way as will be described for the operation on a live subject, and go ahead making your observations in cockerel anatomy.

An empty barrel, bottom side up, may be made to answer for a table, the fowl being held by means of one stout twine tied around the wings next the body and another tied around the legs, the

Operating free ends of both hanging down on the side of the barrel and weighted with a brick or piece of iron. I would put padding of some kind, a piece of old carpet or a rag, npon the barrel head under the chick, thus giving him as comfortable a rest as possible under the circumstances. This kind of operating-table, however, is a poor makeshift at best.

When you have a large number of cockerels ta 
operate on, or set out to caponize your surplus roosters for profit, year after year, as you should, you will want a more convenient table. Dow, and others, advise you to have a table made for this special purpose in as simple a style as you please, with cleats around the top at the right to prevent the tools from falling off, a two inch hole in the center at the left, with a weighted lever underneath and a mortise six to eight inches long from right to left, also in about the center of the table, with a sliding lever, weighted underneath. A twine loop is fastened on each one of the levers, passed up through auger-hole or mortise, and slipped one over the wings, the other over the feet, thus securely holding the subject for the operation.

You can also make a table such as is shown in

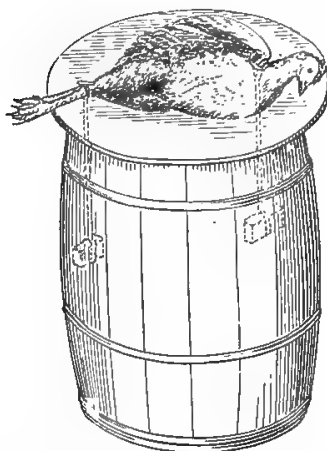

Fig. 1. Barrel as Ophrat ING TABLF.

Fig. 1. It consists of a round board larger than a barrel-head, resting on an empty, headless barrel. Weighted straps or bands are drawn through two holes bored at proper distances, and hold the chicks' wings and legs, as may be seen in the picture. This table has the advantage that you can turn it toward the light to suit, without moving the barrel. But it affords no good chance to. place the tools and is not excessively handy.

The table I use is illustrated in Fig. 2. It is a light, cheap kitchen table, such as we happened to have to spare, three and a half feet long and twenty- 
two inches wide, more than large enough to accommodate the cockerel and leave plenty of room for the tools, and yet light enough to be easily shifted about for the sake of getting the light just right upon the work. I fastened some narrow cleats with screws all along the margin of the right-handed half

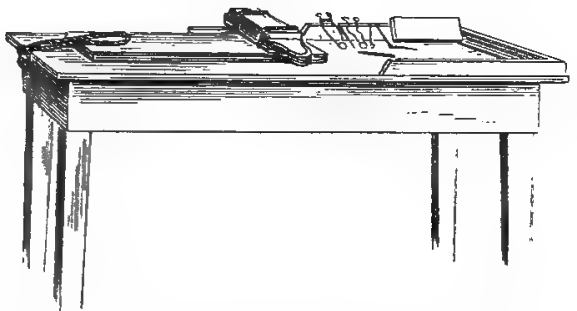

Fig. 2. Greiner's Operating Tabie.

of the table, thus rendering this part a safe place for the tools and accessories. At the middle of the opposite (short) side, screwed into the edge, is a screw-eye or hook, which holds the loop of twine after the latter is slipped around the wings of the victim next to its body. Its legs are held by a strip of board, which is padded with flannel on the under side, and weighted on top with a piece of iron or a brick securely fastened with wire or twine. One end of this lever is cut in convenient shape for a handle, while the other has a cleat which simply hooks over a longer cleat screwed fast upon the table. This arrangement allows the lever to be moved sideways, according to the size of the fowl, or entirely taken off when the table is not in use. The cleats may also be removed by taking out the screws, and the table be put back where it belongs, in kitchen, buttery or cellar. 
I always place a piece of old carpet, an old fertilizer sack or something similar under the fowl, doubled or rolled up to extra thicknesses under the legs, thereby securing a close tit and a firm hold without unnecessary pressure upon the fowl's legs between hard objects.

The only thing that does not yet suit me exactly about this table is the lever. Instead of making it heavy by iron weights, I shall hereafter make it light and springy, fasten the rear end to a wire on which it can slide to the right or left, according to size of bird, and hold it down in front by slipping a wire catch over the end. This will hold the bird more securely in its place, while the bending lever and springy wires will prevent undue pressure upon the bird's legs. 


\section{V. \\ TOOLS AND OTHER REQUISITES.}

TOOLS BES'T SUITED FOR THE BEGINNER.

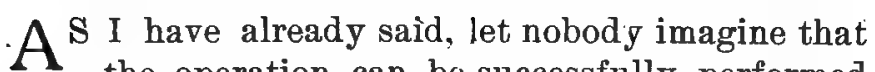
the operation can be successfully performed without the proper tools. They need not necessarily be expensive. Indeed, such tools as I have found most serviceable can be bought for about $\$ 2.50$ a set. I have Itried the sets of several different makers, and most of them serve their purpose quite well, although none are perfect. At present I prefer a combination of several. A per-

The Lance. fect set should consist, first, of a knife or lance. In an emergency, an ordinary pocket knife, sharpened to a razor edge, might answer, but it has not the best shape for the work, and is a makeshift at best. A lance as shown in Fig. 3, and made of a piece of steel one-sixteenth of an inch thick,

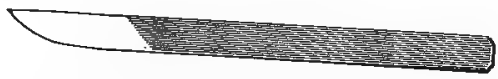

FIG. 3. THE KNIFE on Lande.

seven sixteenths of an inch wide and about six inches long, rounded off to a point on one side and end, is just the thing. Have an oil-stone handy and 
keep the lance well sharpened. The knife as made by some manufacturers has a straight edge. I'prefer to have it well rounded, as then you can make the incision with one dip, and yet without having to go very deep with the point as you have to do with the straight-edged knife.

Next you need a spreader. A whale-bone spreader was formerly much used. We now have wire spring The spreader. $\begin{aligned} & \text { spreaders that are much simpler, and } \\ & \text { much more convenient to use. In }\end{aligned}$ fact, I think the simpler the spreader is, the better. The one shown in Fig. 4 gives good satisfaction.

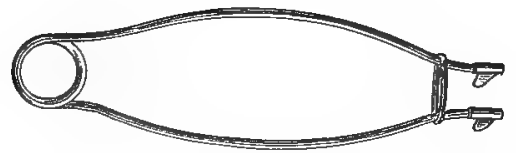

Fig. 4. SPRING Spreader.

Still simpler and cheaper is the wire spreader shown in Fig. 5. There are various other styles of spreaders

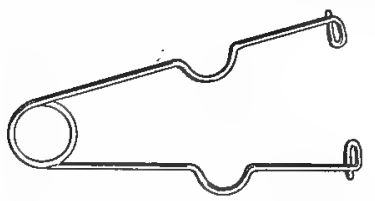

Fig. 5. Wire Sprieadhr.

that can be safely used, but those here illustrated are as serviceable as any, and have the advantage of simplicity.

Next comes a pair of nippers, or forceps, something like Fig. 6. It is used to hold a

The Nippers. little piece of sponge with which to mop up blood inside the capon, or to pick up any stray 
object that may have fallen on or among the intes-

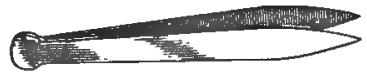

Fig. 6. Pajr of Nippers.

tines. Almost any ordinary small nippers will answer the purpose.

The set should also contain a small, sharp steel

Fig. 7. STHEL, НоOK.

hook (Fig. 7) and a probe (Fig. 8). The former is used to tear open the thin, film-like Hook membrane which envelops the intestines; and Probo. the latter to push the intestines back when crowding over the testicle, or in the search for any object fallen among the intestines.

The most important of all caponizing implements, however, is the canula, with which to catch and remove the testicles. Spoon nippers or forceps are

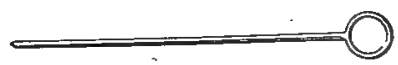

Frg. 8. Probe.

often. used in place of a canula, but they are not safe in the hands of a beginner, and I would not use them under any circumstances. To operate on small (two-pound) cockerels of breeds that have not the worm-like testicles of the Brahma, I prefer the canula with horse-hair (Fig. 9) as I find it in the set obtained from George Q. Dow, North Ep-

conulas. ping, N. H. This is a brass tube about four inches long, a quarter of an inch wide at the 
wide end, and tapering to less than one eighth of an inch. It is closed at the small end, with the exception of two holes large enongh to admit a horse-

Fig. 9. Dow's Horge Hair Canuta.

hair or a small steel wire. Horse hair works well in ordinary cases, and when one breaks another is soon inserted, so that it forms a loop of proper size at the small end of the canula. Occasionally the testicle is of such a shape or in such a position that all the beginner's efforts to slip the hair over the testicle and between it and the artery remain futile. In that case I would try wire in place of the horsehair. Wire, being stiff and unyielding, is easily pushed over and around the organ, and the latter taken away, especially if you use the wire canula illustrated in Fig. 10. This I got in the set from

Fig. 10. Pilling's Wife Candla.

Geo. P Pilling \& Son, Philadelphia, Pa. I think it is well enough to have a canula of this kind on hand, especially if you operate on Brahmas, etc. Still, the other canula will do in an emergency.

Of other requisites you will need a sponge or piece of sponge, and a few cents' worth of carbolic acid. Also keep a few hairs out of a horse tail on hand. That is about all.

Once more let me say, don't try to get along with clumsy imitations and substitutes. For good work, and satisfactory work, you need good tools. If you 
wish to caponize at all-may the number of cockerels to be operated on be half a dozen or a thousand-the first thing to do is to get a complete set of tools. They are cheap enough, and they will last you a life time.

If you once learn the operation, easy as it is, you will have calls from neighbors and others, and possibly you may find a little work at better wages than is paid for ordinary farm work. If you once learn the operation, I am sure you will not allow a worthless lot of roosters to infest your premises, bother your laying hens, and eat three times more than they will be worth in the end.

If you do not feel able to invest the small amount for tools, don't undertake the job of caponizing. For the sake of humanity and decency, don't murder poor brutes with clumsy tools. Be merciful. When properly performed, and with the tools here described and illustrated, the operation involves no element of cruelty. The birds seem to suffer slightly when the incision is made, but for a moment only, and again when the testicle is twisted off, but at no other time, and they are ready to take their meal as soon as the job is done.

I do not know that any set now offered for sale contains the exact combination of tools here described. Possibly manufacturers will make changes in their sets according to my suggestions, and put this, my favorite set. on sale before another season comes around. In the mean time I am now having some of "my sets" made, and shall be pleased to furnish them to my friends at a reasonable price. 


\section{VI. \\ THE OPERATION.}

WHEN AND HOW BEST TO PERFORM IT.

THE three months for capon making are July, August and September, but the operation may be performed at any time when you have the right nuaterial for it.

The tirst, and an absolutely necessary thing to do, is to catch the cockerels to be operated on, and shut them up in a convenient coop, so that they can easily be gotten hold of when wanted. Do this in the evening, and then leave them for $\underset{\text { Preparation. }}{\text { Essial }}$ about 36 hours without food or water. The intestines should be fairly empty in order to enable the operator to use the knife without fear of cutting into them, and to give a good chance for work and for seeing what one is about. The long fast will not hurt the chicks, but only make them terribly anxious for the next meal.

On the morning of the second day, when the sun 
is two or three hours high, and the sky nearly or entirely cloudless, the operation may begin. The expert can manage to get along without much direct sunlight, but the light cannot be too good for the beginner. A clear day is absolutely necessary for a first trial, and if the day should be dark, the cockerels may be given a very small quantity of soft food, to carry them over to the next (supposedly clear) day. Artificial light, with reflectors, etc., as used by some experimenters, is not available for the ordinary farmer and beginner in caponizing, and not needed on an average fair day.

Set the caponizing table in a convenient spot and in direct sunlight, or on a clear, hot day of midsummer perhaps, under the rather open branches of some solitary tree, the foliage of which permits the passage of occasional rays of sun, giving a slightly subdued or modified but direct sunlight.

In all these things, of course, the judgment of the operator should be consulted.

Spread the tools out on the cleat-enclosed part of the table On another table, stand, barrel or box, close by, have a dish with warm water seasoned with a few drops of carbclic acid, also a larger piece and half a dozen small pieces of sponge. The latter may be of about the size of robins' eggs or hickory nuts.

Now pick out the first victim. Let it be a rather lean bird, weighing not more than two pounds, nor much less. Twist or wind the twine

securing the loop around the wings close to the body,
Bird. and standing in front of the table, with the cleat-inclosed end to the right, fasten your vic- 
tim on his left side upon the table, as shown in Fig. 11. Next to the hip, and where, in a lean bird, the

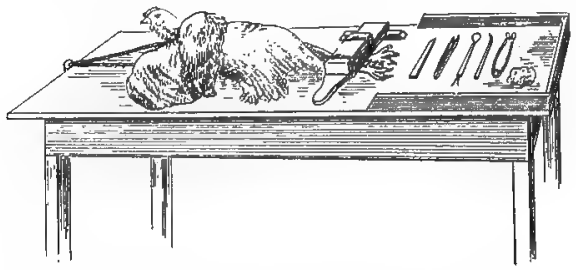

Fig. 11. Bifd Ready for Ophration.

ribs show quite plainly, you find a spot which, because usually covered by the wings, is almost bare. There may be a dozen or two of pin feathers. These should be pulled out. Take hold of them between thumb and index finger, not one by one, but as many as you can take, and deftly pull them out. Don't be nervous. Go at it as if you meant business. If you are quick and determined about it, the removal of these small feathers does not cause much inconvenience to the bird, for the latter never makes any fuss over it. The spot thus cleared need not be more than one and one.half inches in diameter.

At this stage of the proceedings I take the sponge out of the water, squeeze most of the water out of it, and then wipe it over the chicken's side. This is not absolutely necessary, butit moistens the feathers around the bare spot, and keeps them better out of the way.

Now comes the incision. The right place to cut is between the last two ribs; that is, the two ribs next to the hip. In a lean chicken they are easily recognized, and often they are very prominent. They extend from the back-bone for an inch and a 
half or two inches in a slight curve, then take a sudden turn upward toward the breast. Usually the "joints" in the two ribs appear plainly and prominently. Just look for the two slightly raised, whitish, almost knob-like spots. Often the two ribs lie quite closely together, and perhaps the end of the muscle -a flat layer of flesh -extends over them. An examination of Fig. 12 will give you a pretty clear idea where to look for the spot. Here the loca-

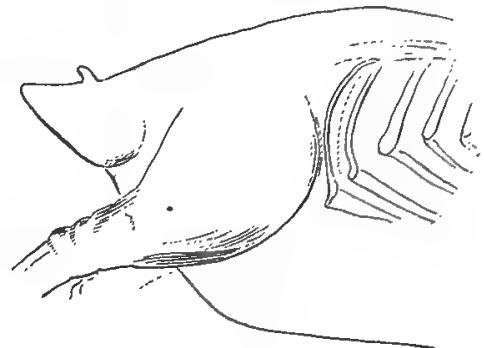

FIG. 12. Location of RIBs. tion of ribs is plainly shown. The dotted line between the last two ribs is the right place for making the incision.

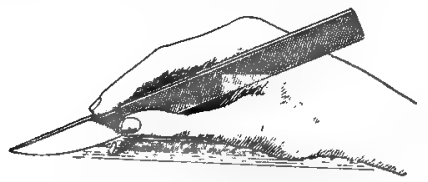

FIG. 13. HOLDING THE KNIFE.

Now proceed by taking the knife in the right hand as shown in Fig. 13. Then with the left hand, reaching over the right, push the skin and muscle from the bared spot toward the hip and hold it there. Observe the two whitish little spots which form the joints of the last two ribs, and set the point of the knife right

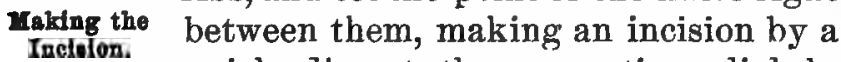
quick dip, at the same time slightly drawing the knife between the two ribs toward the back bone. The length of the incision should be about one inch. With the intestines nearly empty there is no danger of injury to them, even if the 
point of the knife should dip half an inch deep through the ribs. Minor blood-vessels usually extend in the skin across where the incision is to be made. If they are cut, a few drops of blood will be spilled; that is all. But in pushing skin and muscle toward the hip, and drawing it tightly, you may at the same time aim to get the blood-vessels somewhat out of the way of the knife. If this is done, the knife often does not draw a drop of blood. If the wound bleeds badly, the moistened sponge may be pressed upon it for an instant to absorb the blood. Making the incision, of course, will cause a momentary pain to the bird, but it is no more than any living thing has to endure a good many times in life, and will do so without complaining.

After the incision is made, lay down the knife and take up the spreader, all the while holding the skin back toward the hip with the left hand. Press the spring of the spreader together Jsing
spreader. until the two free ends meet, and then the spreader. insert them in the opening and let go. Also release the skin yet held with the left hand. The spreader will push the ribs apart, leaving an opening to the fowl's inside from one-half to threequarters of an inch wide. If the cut was not large enough, you can remedy it by a slight touch of the knife to one or both ends of the incision.

From now on in the proceedings you will need good light. Shift the table about, or turn it as required, so that the best light will reach into the opening and upon your work. Lsooking down through the incision, you will notice a thin, translucent film or membrane, which covers the entire in- 
ternal organs. The little blood which may have dropped in from the outside wound and clotted on this membrane, is most easily removed by picking up, with the tweezers or forceps, a little piece of moistened sponge, introducing it into the opening, and pulling it out again with all the blood adhering to it. The membrane now appears clean Lotting and translucent. Then take up the in tho Llght. steel-hook and carefully pick this mem. brane to pieces, always holding the sharp point of the hook upward, or in the direction of the backbone, in order to avoid touching the organs that may be crowding against it from below. The tear through the membrane must be large enough to expose, nnder good light, the internal organs to view. When bowels are nearly empty, you will plainly see, well toward the back-bone, the upper testicle, a yellowish body of about pea size (of course, larger in older cockerels), perhaps somewhat elongated, or in the Brahma, etc., quite long, almost worm-like. Sometimes both testicles come in plain view, especially if you push the intestines aside with the probe or with a similar tool. Sometimes, again, it happens that the intestines crowd upon the upper testicle and hide it from view. Then introduce the probe and push them aside, and the testicle will come in full view. Its light color (although often it is partially dark-colored, almost black) makes it plainly visible.

You are now coming to the object of all this proceeding; namely, the removal of the testicle. Take up the canula. The single horse hair should previously have been adjusted to form a loop of about 
or nearly three-eighths of an inch in diameter. Slip this loop over the testicle, and between it and the big artery which may be seen along-side Removing the
Testicle. try again. It may require several trials, but don't lose patience. It will go all right at last. In especially bad cases you may take wire in place of the horse-hair; but the latter is usually to be preferred, and if the testicle is in normal condition, a little perseverance will surely lead to success. When you see that the loop has properly caught on, draw up on the loose ends of the horse hair, at the upper end of canula, so that the loop is all pulled in, and the testicle tightly drawn up to the end of canula. Hold the canula with the left hand, twisting it back and forth about half way around, at the same time pulling continuously and strongly on the ends of the horse-hair with the right hand, thus cutting and twisting the testicle off its fastenings. When you feel it give way, pull it up with the canula and horse-hair, and if some of the strings still adhere to it when you get it up through the opening, cut them off with the knife so that a little bit, say $\frac{1}{32}$ of an inch, remains on the testicle. This is important. If you cut too close to the testicle, nature may try to thwart your purpose by letting a new growth of testicle take place, thus causing what is know as a "slip."

The thing to be avoided is injury to the big artery. If the blood-vessel should form a kink, and the kink be drawn into the horse-hair loop, the artery will be torn, and the fowl will bleed to death in a few minutes. With reasonable care, however, this does not often happen. 
Now one side is done. All that remains to be done is to see that no feathers or other foreign substance are left inside the opening; then take out the spreader, let the skin and muscle slip back over the incision through the ribs, unfasten the chick, andturn him around on the other side for another operation.

I have described the job in all its minutest details. To perform the operation does not require one-tenth the time that it takes to tell it. In the first attempt you may possibly spend a quarter of an hour or more. What does it matter? Take your time. The fowl, while not especially comfortable, is not actually suffering. He feels slight actual pain only during the moment when the incision is made, and perhaps during the removal of the testicle. After you have operated on two or three birds the task becomes an easy one, and the operation will not take many minutes. The difficulty is only in the first attempt. Expert operators usually remove both testicles from the one opening, the lower one first and afterwards the upper one. This is all right, but it is not safe for the novice to attempt it. I find it much easier, more convenient, much safer, and just as expeditious to open the fowl on both sides.

The turning of the bird is quickly done. Lift up the lever, taking hold of the chick's legs, turn him over on his right side, as shown in fig. 14, and readjust the lever to hold his feet. Again shift the table "so the light will fall fully apon the front of the fowl, and into the opening to be made on the left side. The operator this time stands on the other 
side of the table, next to the chick's back, as before. Then a few feathers are plucked out, the moist sponge wiped over the bared spot and the surround-

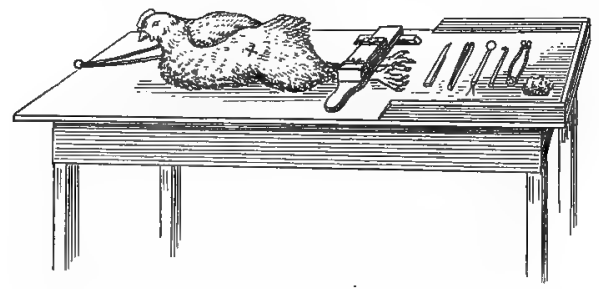

Fig. 14. Brrd Ready for Second Operation.

ing plumage, the incision made and the whole operation gone through with in exactly the same manner as was done on the other side. The fowl is placed in a rather more convenient place to be operated than when lying on its left side. A good deal of bleeding is sometimes going on after Removing the testicle is removed. While a second Testicle. little blood if left inside among the bowels, would probably do no harm, there may be more than the system can absorb in a natural way, and the clotted gore might harden and cause inflammation, blood-poisoning and death. At any rate it is advisable to remove this blood by the means already mentioned; namely, mopping up with little bits of moistened sponge. Sometimes you will have to introduce one bit after another, half a dozen or even a dozen times, letting the sponge soak up, then withdrawing it with the tweezers, and squeezing it out in warm water. At other times there may not be a drop of blood spilled. If that is the case, or 
otherwise when the flow of blood ceases, see that no feather, bit of sponge or other foreign article is left inside; then withdraw the spreader and unloosen the bird. Next mark it in some way to show that it has undergone the operation. One

Marking the
Capon. that is to clip off the end of one toe. All my capons have a stub inside toe on the left foot. The style of marking is a matter of individual choice. You can use one of the 25.cent chicken markers with which to punch a hole or two through the web between two toes; or you might use wire rings, or any other of the various devices. A stub toe, however, suits my perpose as well as anything. Put the fowls foot upon the table, hold a keen knife blade across end of toe to be amputated, with knife point down upon the table, and then with a quick move press down the handle of the knife, like a lever, and thus clip off the toe end. It seems to make no particular difference to the fowl, either at the time that it is done or afterwards.

Of course, you will occasionally lose a bird. When in removing the testicle you rupture a big blood vessel, the bird will die under your hands, usually in less than ten minutes. In that case, chop his head off, if you so prefer, and have a fine springchicken dinner. Accidents of this kind, however, should not occur oftener than once in fifty operations on ordinary fowls, even with the beginner. But if they do occur there is no loss, as the bird has its full value for table use. A capon that comes out alive after the operation, is " out of the woods," and complete recovery is swift. 


\section{VII. \\ THE AFTER TREATMENT.}

\section{HOW TO HASTEN THE HEALING PROCESS.}

MY elaborate description of the whole operation of caponizing may lead many of my readers to imagine that the capon is in bad shape when he comes from the operating table. This a mistake. The testicles are not a vital part. Their removal is of little consequence so far as the bird's health and vitality are concerned; the only difference it makes is in regard to the sexual development of the bird. The thin membrane which envelops the intestines is not a vital part. The holes which we have torn into it are an injury which amounts to almost nothing. The only real injuries inflicted, therefore, are the two incisions, and these are merely flesh wounds of the simplest character, and by no means severe. The skin having slipped back in its natural position, covers the flesh wound between the ribs; the cut in the skin, and that in the flesh, on each side, cannot well be in more farorable shape for rapid healing. There is no need of sewing the edges of the wound together, or using any kind of salve, or plaster, or wash. Just trust in nature, the boss physician, and you will not be disappointed.

At the beginning of the eaponizing seasor, I put up what I call my "capon hospital." This is simply a space on one side of the barn containing,

Capon
Hospital. surface to each capon, and covered with a 
low roof as a protection from rain and sun, and tightly enclosed with wire netting. Inside is a coop in which the convalescent fowls spend the nights. A box in one corner is kept well supplied with soft food (bran and meal moisted with skim-milk), and a dish in the other corner contains the water, which should be frequently renewed. Some of our instructors tell us to feed lightly at first; others advise giving all the food that the birds will eat. I usually have tried to keep the box supplied with food all the time, but it is a hard task, for the birds have a keen appetite and eat a great deal. Just as soon as a capon is put into the "hospital," and once gets sight of the feed-box, he will forget all the trials which he has just experienced, and at once proceed to fill his crop. It is well to keep the birds confined in close quarters for at least eight days after the operation. Many of them "wind-puff" badly, a lot of air gathering under the outside wind-Puff. skin and giving the capon a puffed-up appearance and probably causing much inconvenience. I usually looked the confined birds over once a day, and gave speedy relief where needed by pricking the puffed-up skin with the point of a keen pen-knife. Part of the birds do not need this attention; others wind-puff right along for a week or so, and need frequent touches with the pen-knife. Usually you can tell by the appearance, and always by the feeling, whether there is wind-puff and cause for treatment. In consequence of this confinement, of the treatment and of their voracious appetite, the capons become exceedingly tame and tractable.

On some occasions I have given the capon his full 
liberty right after the operation, letting him run, feed and roost with the rest of the fowls. Neither this liberty, nor the dry (grain) feed, nor want of prompt attention, when wind-puffed, seemed to retard his perfect convalesence. If I noted an especially puffed-up appearance, I would perhaps catch the bird and give him relief with the knife. Still, I believe it is a good plan to keep the birds confined for from eight to ten days, giving soft food and proper attention otherwise. The straw, leaves or soft earth on the floor of the "hospital" should, for the sake of cleanliness, be often renewed.

When the period of convalescence (eight or ten days) are past, I give these capons their liberty. They will not wander off very far, but stay most of the time near where they are accustomed to get their regular rations. At night I drive them into the "capon house," a warm stall with low capon House. roosts, regularly cleaned and disinfected. Capons do not seem to be particular about their roosting place. I try to keep my hens and capons apart at night, hen house and capon house being only separated by the width of the barn. But when a capon happens to be nearer the hen roost at the time he wants to retire for the night, he forgets where his place is, and unhesitatingly takes lodgings with the hens. On the other hand one can safely crowd two or three times as many capons into a building as hens. Crowded hens will not lay well. Crowded capons eat and grow just as fast as they would otherwise. 


\section{VIII. \\ FEEDING FOR MARKET.}

HOW TO OBTAIN BEST RESULTS AT LEAST COST.

$T^{H E}$ chief aim, from the time the bird is caponized to the time of sale or slaughter, should be to produce the heaviest possible weight, and for this reason a liberal supply of flesh-forming food should be given. During the summer and earlier fall months I feed mostly bran slightly mixed with corn meal and moistened with skim-milk or buttermillk, and whole wheat. Corn is not a proper food then; but some variation is provided summer Foeding. for by giving an occasional mess of peas, buckwheat or oats. My fowls have free range, and find good pasture on the lawn and in a piece of rye and rape sown for this very purpose close to the barn. Grasshoppers, bugs, worms, table-scraps, etc., all help to fill the fowls crops and to produce capon meat. A ressel in the yard is kept supplied with skim-milk almost all the time.

All quick growing animals have good appetites, and young capons seem to be always hungry. Notwithstanding their tendency to laziness, they are good foragers.

The problem of profitable feeding during the sum- 
mer and early fall, indeed during all mild and open weather, is comparatively an easy one to solve. Fowls on free range find so much to pick up in nice warm weather that small additional rations of grain will suffice to keep them in good growing condition. The natural advantages seem to me all in favor of that climate which allows fowls to be out on pasture the greatest number of days during the year; and if I were to make it my chief business to raise "capons for profit," I think I would try to locate in a country with mild, dry, open winters, and on dry sandy soil. With us at the north the problem of feeding capons grows in degree of complication and difficulty with the severity of the winter. When we aim for largest size in capons, as we should, we will have to keep winter Foeding. them until they are about one year in our markets for capons until February or March. Before that time they would not bring much higher prices than ordinary fowls. After that time the prices range from 18 cents per pound upwards. In short, if we wish to secure largest possible size of fowl, and largest possible price per pound, we have to keep the capons all winter and perhaps far into the spring. Now anybody who has ever wintered fowls on purchased food, knows that they eat a great deal, and that the bills for grain, even when wheat is only 60 or 65 cents, and corn 50 cents a bushel, soon run up to a large amount.

The trouble is that many people think grain is the only, or even chief poultry food. This is an error. Exclusive grain diet is not only expensive, but also unnatural and unsafe. It may do well for a week, 
when fowls are being fattened for slaughter, but if long continued, it will surely clog the system, make fowls over-fat, and in the end injure their general health and well-being. It should be understood that the tendency in capons, especially in cold and stormy weather when kept in enforced idleness, is to grow and lay on fat. Even without excessive feeding they are bound to get fat as butter.

What is needed, in the first place, is a cheap, bulky material that will fill the fowls'.crops, taking the place of the grass and leaves of Bulky Food summer. Then we want a little moderate amount of grain to add substance and warmth in place of the weed seeds and the like found scattered about in the open season, and finally, something in place of bugs and worms.

The bulky material is best and most cheaply supplied in chopped regetables and chopped clover hay. Every fall I store a lot of beets, carrots, turnips, kohlrabi, etc., in the cellar, and cabbages in the barn or out-doors, for the very purpose of utilizing these vegetables for winter poultry feed. Cabbages are for the most part simply thrown into the hen or capon houses as needed. Roots of all kinds, also small potatoes and apples, are chopped up in a plank box with a sharp spade, then (sometimes slightly salted) mixed with a little bran and fed in their raw state. In cold weather a mess of beets, turuips, carrots, pumpkins, squashes, small potatoes and peelings of all kinds cooked in a big kettle, and stirred up with bran to a thick, crumbly mass are greatly relished by all fowls as a warm breakfast. Chopped clover hay, and the chopped leaves of 
corn stalks, are scalded, sprinkled with bran, and then fed warm. In short, with materials of this kind we can keep the birds' crops well filled at a very small cost.

But one can make this food even much richer at little additional expense. Green bones, with more or less meat on them, are a waste product of butcher shops. The proprietors usually are glad if somebody comes to take it away. At any rate this richest and (when fed in reasonable limits) best of all poultry foods can be had at a very slight expense. It is a most excellent substitute for the bugs and worms of summer. It is a pity so much of it is wasted.

The question only arises how we can get the hard bones, and the tough gristle, and other fleshy mat-

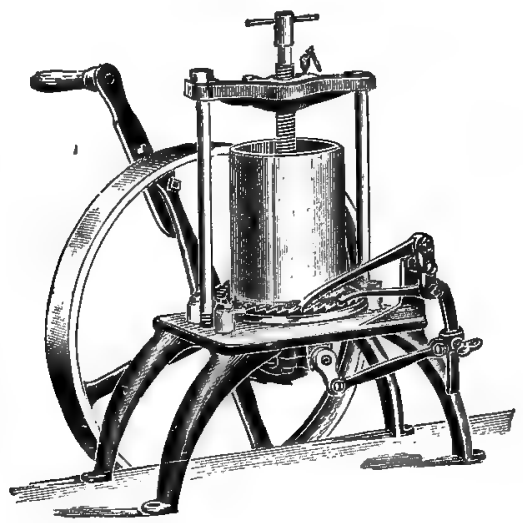

ter fine enough for fowls to eat. The often-advertised $\$ 5.00$ bone mills will not grind green bones. Two ways are open for us to utilize these waste products. They can be softened by steaming under high pres- 
sure. It might pay us to get a steam cooker suited for the purpose. On the whole, Vtilizing
Bones and Vegetmbles. however, I believe that it is preferable to cut bones, gristle, flesh, etc., with one of the cutters now especially designed for that purpose. The accompanying illustration shows one of these-machines. It does not grind, but will cut or shave any of the materials named in pieces fine enough for fowls to eat. It is manufactured by Webster \& Hannum, Cazenovia, N. Y., and sells for $\$ 12$. I think this is a good machine for people who keep a moderate number of fowls. Where many hundreds have to be fed, a power machine will be preferable.

Now and then a little grain-wheat, oats, buck' wheat, etc., should be given, and the evening meal should always consist of whole grain, chiefly of corn in very cold weather. If plenty of the cheaper and more bulky food is given. four quarts of whole grain would be enough for one hundred fowls.

That fresh water should at all times be kept within reach of the birds need hardly be expressly stated. They should have no chance to drink out of stagnant pools in the barn-yard. Another thing needful is a free and continuous supply of sharp grit. I do not think that there is anything superior to raw limestone broken into pieces of pea size or smaller, although ground oyster shells or sand containing coarser particles will answer.

This grit is as necessary for satisfactory results as food. Without the required grit food cannot be properly digested, and a large part of it will be wasted. 


\section{IX. \\ THE CAPONS IN MARKET.}

\section{HOW TO KILL, DRESS AND PACK THEM.}

THE first thing is to decide about the market.

Have some understanding with a good commission house in the city, or with a large hotel or retail dealer, and act on advice and suggestions received from your buyer or middleman. Keep the birds in confinement at least twenty-four hours before killing, entirely withholding food and water. You want their crops to be entirely empty.

You need a thin-bladed, sharp-pointed knife, the regular French killing knife which retails for 50 cents, being, perhaps, preferable to all others. For killing and dressing select or arrange a cool. welllighted shed. Fasten two pieces of strong twine to a beam overhead, say a foot apart, and let the lower ends, each of which has a "slipping zilling capons. noose," hang down to within three or four feet from the ground, or just at proper height to be most convenient for plucking the fowl. Fasten one of the capon's legs in each of the nooses, letting his legs hang downward. Then holding the knife in the right hand, take hold of the bird's head with the left, and open his bill widely. If the light shines 
well into the throat, you may quite plainly see the big jugular vein on each side. Insert the point of the knife, and sever these blood vessels by a quick cut across. The blood will at once follow the knife, and flow freely in two big streams. Without further delay run the point of the knife through the roof of the mouth clear into the brain. The bird now is so near dead as to be without sense of feeling. Just at this time, also, the feathers come off quite easily, and no time should be lost. Suspend a two ponnd weight attached to a hook from the bird's lower bill. Of course you are clad in old clothes, and ready for the muss. Take good hold of the bird, and strip off the feathers as quickly as

possible. Leave on the feathers of the

Dreaping the head and neck (hackle-feathers) all the
Bird. tail feathers, with a few feathers up towards the back, and the long feathers on the hips close to tail, also the feathers on the legs half way up the "drumsticks." Be careful not to tear the skin.

This peculiar style of dressing is a kind of trademark, and serves to distinguish the capon at once from any other fowl in market. The head, with its shrunken or non-developed comb and wattles, should always be left on the bird. Remove all traces of blood from his head and month by careful washing with cold water.

A table should be on hand upon which to dress the bird, also a trongh or box withont ends and cover, just large enough to hold him in best position, back downward, for the removal of the intestines. Carefully cat around the vent, and pull out the 
intestines. You will find a heavy layer of fat around the opening, and the intestines covered with it. As you pull out the intestines, push the fat back into the bird, and when you come to the end of the intestines push your finger up into the body, along the intestines, and separate them from the gizzard, leaving everything else inside the bird. The layer of fat around the vent may be turned slightly outward and thus allowed to cool and harden. The bird will look all the better for it. Then hang him up in a cool place. When thoroughly cold he will be ready for boxing and marketing.

New, clean boxes should be used for shipping capons. Nothing, in fact, must be neglected to make the packages as well as the capons look neat and attractive. Line the boxes with clean white paper. Printed paper should never be used. Pack the birds down in layers, backs up, as solidly as can be, yet without bruising. You will have no difficulty in finding a market for nice, large, fat, welldressed and well-packed capons at acceptable and profitable prices. 


\section{$\mathrm{X}$. \\ ODDS AND ENDS.}

TURKEYS AS INCUBATORS AND CAPONS AS BROODERS.

THERE are a few people who make a success of hatching eggs and bringing up chicks by artificial methods. Most of us, however, will find it easier and safer to stick to Mother Nature's good old ways. It will not be a new thing to many of my readers when $I$ tell them that a tarkey hen can be utilized as an incubator. She can be made to sit at any time of the year, and for an almost indefinite length of time. We want early chicks, but cannot always succeed in getting them, simply because our hens do not get broody

Turkeg Hen as early enough in the season. The
Incubator. Incabator. turkey hen then comes as a deus ex machina. A writer in Country Gentleman gives the following directions how to manage her: "Select a turkey hen in her second year; arrange a nest, in which put a number of eggs, either china or ordinary eggs filled with plaster of Paris. Place the turkey upon the nest, and cover her with a bar. rel, preferably one made for sugar, as it is lined with blue paper. This excludes the light; darkness 
is necessary. Leave the hen to her meditations for 24 or 30 hours, or longer, after which time she will sit contentedly for two months, leaving the nest only for food and drink. Take away the artificial eggs, and put those under you wish for chickens. When these are hatched, remove the young birds and replace with fresh eggs."

Now we will press the capon into service, making him serve as brooder. The writer already quoted, says in the same journal: "Choose a large, fine capon, not too young. Envelop his Capon
Brooder. head in your hand, and puff into his bacco pipe, the stronger the pipe the better. Shake the cock's head after each blowing, repeating for five or six times until the bird seems unconscious; then place him on the young chickens and set the box in a dark corner for some six or eight hours, or until the next morning, when this hypnotized capon will carry and care for these young birds like a hen. In my hands this has proved eminently successful, and I commend the process to all." 
Poultrymen!

Green cut bones will make more eggs than any FOOD known. Fowls fed on CUT BONE will nearly double the egg yield in two weeks. We have the best, cheapest and most practical Bone Cutter yet pro-

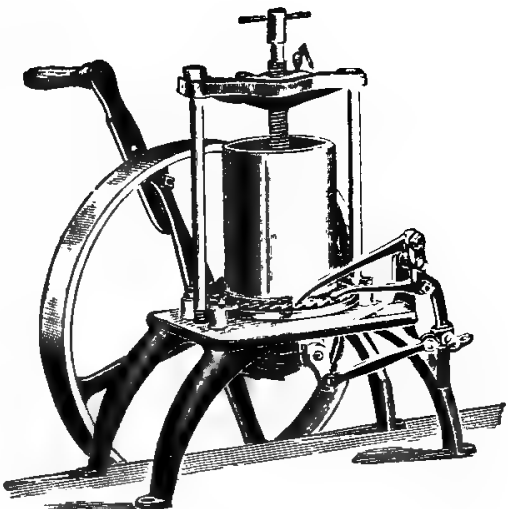
duced. Highest Award and Medal at World's Fair. Also first premium at New Tork State Fair, Interstate Fair, Western N. Y. Fair, Nebraska

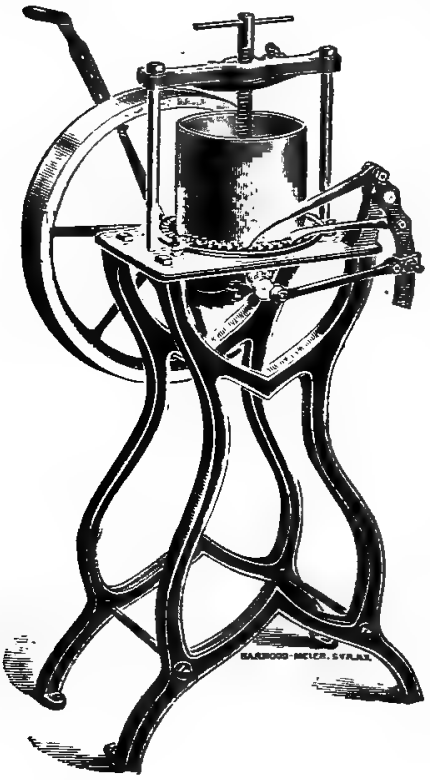
State Fair and scores of local fairs. Get our circulars, prices, \&c., \&c.

\section{Pure, RaW - Limestone Grit}

for fowls, is the best grit known. It contains lime and sharp corners to do the grinding. We furnish this for $\$ 1.00$ per 100 lbs. Get a sample from us, which only costs two-cent stamp.

\section{Webster \& Hannm,}

Cazenovia, N. Y. 


\section{A Periect \\ Caponizing Set, \\ PRICE, = $\$ 2.50$.}

Just such a combination of tools as I wanted, and as I think the beginner needs, was not in the market, so I have had a lot made to order for my special purposes. Every tool in the set is made of the very best material, and all, to avoid expense, are put up in a plain box. The set contains

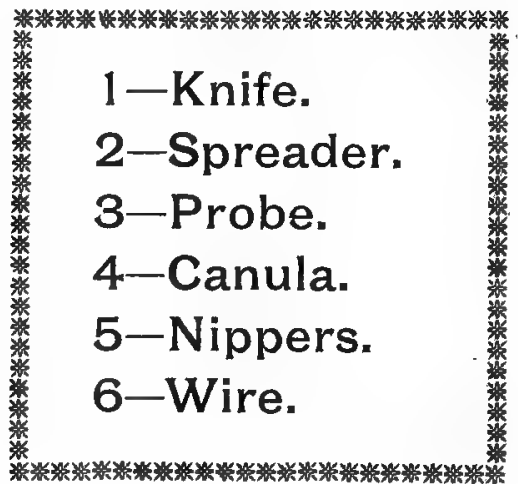

This set will be sent post-paid to any address on receipt of $\$ 2.50$. Remit by Postal or Express Money Order, or in Registered Letter to

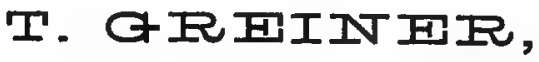

LA SALLE, N. Y. 


\section{LEADING BOOKS}

BY T. GREINER.

HOW TO MAKE THE GARDEN PAY.

The leading work wil grardening. Profusely illustrated.

Printed in clear type. Haudsoncly bound in cloth. 272 pages, $6 \times 9$ inclues. Price, 20.00 .

\section{THE NEW \\ Third revised and en- ONION CULTURE. lurged edition. Copi- ously illnstrated. It} gives all the details of the new method by which 2.000 bushels are easily grown on one acre, as sui bushels in the old war. This srstem makes onion growing both at the Yorth and South a certain success. Price, 51) ct:s.

\section{PRACTICAL FARM CHEMISTRY.}

Tells all about manure and manure application: how money can be saced in the purchse: and inade in the application of fertilizers. PART I.-The raw materials of plant food. PArt II - The available sources of suppl!̣. Part III.Principles of economic application. 163 pages. Elegantly bound in cloth. Price, \$1.00.

Liberal discotst al.lothed to the trade.

Remit price in Registered Letter, Express Mnner Order, Postal Yote, or Post-office Money Order to

T. GREINER, La Salle, N. Y. 


1)

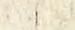

